\title{
Diurnal variation of upper tropospheric humidity and its relations to convective activities over tropical Africa
}

\author{
E. S. Chung ${ }^{1}$, B. J. Sohn ${ }^{1}$, J. Schmetz ${ }^{2}$, and M. Koenig ${ }^{2}$ \\ ${ }^{1}$ School of Earth and Environmental Sciences, Seoul National University, Seoul, Korea \\ ${ }^{2}$ European Organisation for the Exploitation of Meteorological Satellites (EUMETSAT), Darmstadt, Germany
}

Received: 20 October 2006 - Published in Atmos. Chem. Phys. Discuss.: 10 January 2007

Revised: 2 May 2007 - Accepted: 2 May 2007 - Published: 14 May 2007

\begin{abstract}
Diurnal variations of upper tropospheric humidity (UTH) as well as middle tropospheric humidity (MTH) were examined in conjunction with the diurnal cycle of convection over tropical Africa and the adjacent tropical Atlantic Ocean using Meteosat- 8 measurements. Cloud and humidity features were also tracked to document the diurnal variations of humidity and clouds in the Lagrangian framework.

A distinct diurnal variation of UTH (and MTH) is noted over regions where tropical deep convective cloud systems are commonly observed. The amplitude of the UTH diurnal variation is larger over land, while its variations over convectively inactive subtropical regions are much smaller. The diurnal variation of UTH tends to reach a maximum during nighttime over land, lagging deep convection and high cloud whose maxima occurred in the late afternoon and evening, respectively. It was revealed that these diurnal variations over the African continent are likely associated with continental-scale daytime solar heating and topography, in which topographically-induced signals develop earlier around the mid-afternoon and merge into stronger and broader continental-scale convection clusters later, forming a precipitation maximum in the late afternoon. It was also revealed that advection effect on the diurnal variation appears to be insignificant.
\end{abstract}

\section{Introduction}

The diurnal variation associated with the solar heating cycle is one of the most fundamental components accounting for variability in the weather and climate systems. Numerous observational studies have documented diurnal variations of deep convection, precipitation, cloudiness, outgoing long-

Correspondence to: B. J. Sohn

(sohn@snu.ac.kr) wave radiation, and upper tropospheric divergence over the tropics (e.g. Gray and Jacobson, 1977; Duvel and Kandel, 1985; Hendon and Woodberry, 1993; Kondragunta and Gruber, 1996; Chen and Houze, 1997; Yang and Slingo, 2001; Nesbitt and Zipser, 2003; Schmetz et al., 2005; Yang and Smith, 2006). Previous studies commonly show that the amplitude of the diurnal variation is larger over the land than over the open oceans, and that most land regions exhibit diurnal maxima during the afternoon-evening period. By contrast, it has been reported that there exist significant differences in the timing of diurnal maxima over the ocean, leading to various hypotheses for explaining the early morning maxima in association with deep convection (e.g. Gray and Jacobson, 1977; Randall et al., 1991; Chen and Houze, 1997) and studies examining regional differences in diurnal maxima (e.g. Yang and Slingo, 2001; Tian et al., 2005; Yang and Smith, 2006).

The variability of water vapour at various spatio-temporal scales has been an important issue in climate study because of its association with radiative cooling and latent heating and its interactions with the cloud system (e.g. Bates et al., 2001; Sohn and Schmetz, 2004; Zveryaev and Allan, 2005). However, our understanding of the distribution, maintenance, and variation in water vapour is still far from being complete. In particular, the diurnal variation of water vapour in the upper troposphere is not fully understood, despite its importance in regulating/modulating outgoing longwave radiation for both clear sky and cloudy sky. A couple of studies were conducted using radiosonde observations (e.g. Dai et al., 2002; Machado et al., 2002), however, these results represent only a local area mainly over land at a given specific period. Furthermore, the accuracy of radiosonde-observed water vapour concentrations in the upper troposphere is not very high (e.g. Gaffen et al., 1991).

Published by Copernicus Publications on behalf of the European Geosciences Union. 
While more frequent measurements of water vapour channel radiances from geostationary satellites significantly improved the sampling problem of conventional radiosonde observations, there is little literature discussing the diurnal variation of water vapour in the upper troposphere. Udelhofen and Hartmann (1995) studied the diurnal variation of upper tropospheric humidity (UTH) from four days of hourly GOES-7 $6.7 \mu \mathrm{m}$ radiance measurements with a spatial resolution of $8 \times 16 \mathrm{~km}$ and showed that the UTH diurnal variation lags the diurnal cycle of upper tropospheric clouds by about $8 \mathrm{~h}$. Using three months of hourly GOES-7 $6.7 \mu \mathrm{m}$ water vapour channel measurements, Soden (2000) reported a similar phase relationship between land and ocean. The UTH maxima in both land and ocean appeared to lag $3-4 \mathrm{~h}$ behind the upper tropospheric cloud maxima. The results from those two studies were based on measurements over the tropical Americas and the adjacent oceans. More recently Tian et al. (2004) investigated the UTH variations over the entire tropics using three hourly $0.1^{\circ} \times 0.1^{\circ}$ gridded water vapour and window channel radiances from multiple geostationary satellites. They reported that UTH tends to peak around midnight over the ocean and 03:00 local time (LT) over land. In this research, extending these studies with more comprehensive measurements of the European Meteosat-8 satellite (Schmetz et al., 2002b) in space and time domain, we intend to document diurnal variations over the largest land mass over the tropics, namely tropical Africa, and try to understand the physical mechanisms inducing the diurnal variation over the Africa-Atlantic Ocean area.

From comparative studies of the diurnal variation of UTH with those of deep convection and high cloud, it was shown that high cloud precedes UTH and lags deep convection (Soden, 2000; Tian et al., 2004). These studies further suggested that the upper troposphere is moistened by the evaporation of hydrometeors detrained from deep convection centres, where the results were based at individual grid points or in the Eulerian framework. By contrast, however, UTH and high cloud tendencies following the convective system (i.e., in the Lagrangian framework) have the same phase (Soden, 2004), implying that the upper troposphere is moistened by the same dynamical mechanisms responsible for high cloud development, as suggested by Sherwood (1999), and Luo and Rossow (2004).

Recent Meteosat- 8 measurements provide an opportunity to examine such contrasting views concerning the upper tropospheric moistening processes because Meteosat's high spatial and temporal resolution enables an examination of their relationships not only in an Eulerian perspective but also in a Lagrangian perspective. In summary, this study intends to investigate the diurnal variation of UTH (and middle tropospheric humidity: MTH) and its relation to deep convection and high cloudiness over tropical Africa and the adjacent tropical Atlantic Ocean using Meteosat-8 measurements in both Eulerian and Lagrangian frameworks.

\section{Data and methodology}

\subsection{Data}

Meteosat- 8 , which is geostationary above $0^{\circ}$ longitude, scans the full disk of the earth with an imaging repeat cycle of $15 \mathrm{~min}$ and with a $3 \mathrm{~km}$ spatial resolution for IR channels. Out of twelve channels of the Meteosat-8 Spinning Enhanced Visible and Infrared Imager (SEVIRI) instrument we use radiance measurements from the channels centred at 6.2, 7.3, and $10.8 \mu \mathrm{m}$ for UTH, MTH, and cloud classification, respectively. Detailed information on the SEVIRI channel characteristics can be found in Schmetz et al. (2002b). The Level 1.5 images for July 2004 and January 2005 are analysed, particularly over tropical Africa and the adjacent tropical Atlantic Ocean within the $30^{\circ} \mathrm{N}-30^{\circ} \mathrm{S}, 50^{\circ} \mathrm{E}-50^{\circ} \mathrm{W}$ analysis domain.

\subsection{Precipitation index, high cloud, and UTH}

The $10.8 \mu \mathrm{m}$ window channel equivalent blackbody or brightness temperature $\left(\mathrm{TB}_{11}\right)$ is used to determine the degree of deep convection and high cloud fraction. Hendon and Woodberry (1993) defined the deep convective index (referred to as a precipitation index (PI) in Tian et al. (2004)) based on the empirical relationship that colder cloud top temperatures are closely linked to heavier precipitation, i.e.:

$\mathrm{PI}=a\left(230-\mathrm{TB}_{11}\right)$, if $\mathrm{TB}_{11}<230 \mathrm{~K}$

where $a$ is the proportional constant. Although $a$ was determined from the time-mean of the zonal average throughout the tropics, Eq. (1) has been applied with success to study the diurnal variation of tropical convection (e.g. Hendon and Woodberry, 1993; Yang and Slingo, 2001; Tian et al., 2004). In this study, we apply Eq. (1) to each $2.5^{\circ} \times 2.5^{\circ}$ grid box to infer the tropical precipitation associated with deep convection.

For the high cloud fraction (HC), a value of $260 \mathrm{~K}$ of $\mathrm{TB}_{11}$ is used as a threshold (Chen and Houze, 1997; Tian et al., 2004), which roughly corresponds to a level of around $440 \mathrm{hPa}$ in the tropics (McClatchey et al., 1971). In this study, the high cloud cover, defined as the percentage of pixels lower than $260 \mathrm{~K}$ in a $2.5^{\circ} \times 2.5^{\circ}$ grid box, is further divided into deep convective cloud $\left(\mathrm{DC}, \mathrm{TB}_{11}<230 \mathrm{~K}\right)$ and cirrus anvil cloud (CAC, $230 \mathrm{~K}<\mathrm{TB}_{11}<260 \mathrm{~K}$ ) as in Tian et al. (2004).

The UTH is defined as the approximate mean relative humidity over a layer between $500 \mathrm{hPa}$ and $200 \mathrm{hPa}$ in clear sky. It was shown that the brightness temperatures of the water vapour channel centred at $6.2 \mu \mathrm{m}\left(\mathrm{TB}_{\mathrm{WV}}\right)$ is linearly related to the natural logarithm of UTH divided by the cosine of the viewing angle $\theta$ (Soden and Bretherton, 1993), i.e.:

$\ln (\mathrm{UTH} / \cos \theta)=a+b \mathrm{~TB}_{\mathrm{WV}}$ 

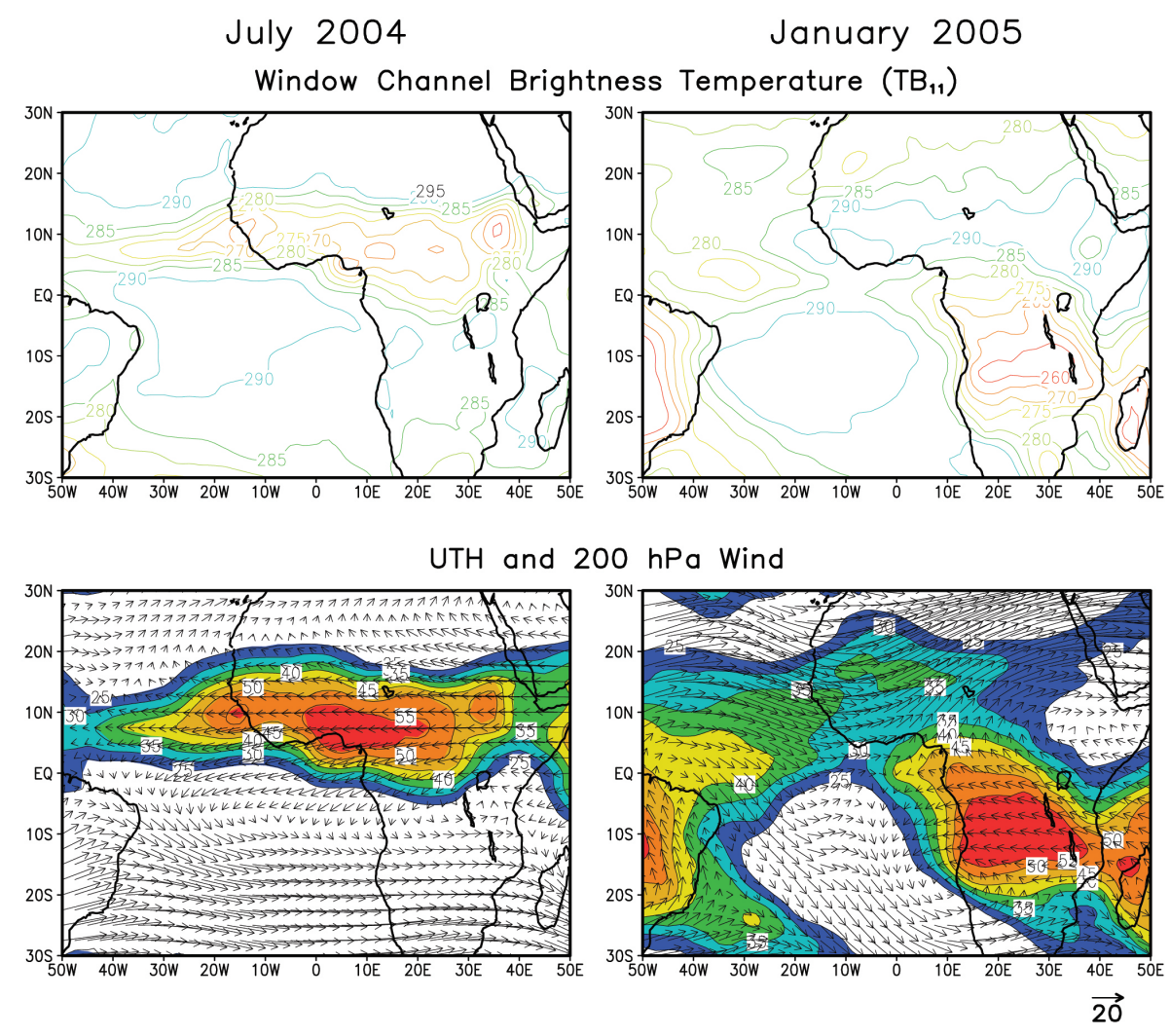

Fig. 1. Geographical distributions of monthly mean $\mathrm{TB}_{11}$ (top) and UTH (bottom) for July 2004 (left panels) and January 2005 (right panels). Units of $\mathrm{TB}_{11}$ and UTH are $\mathrm{K}$ and $\%$, respectively. The $200 \mathrm{hPa}$ wind fields (unit: $\mathrm{m} \mathrm{s}^{-1}$ ) from the NCEP/NCAR Reanalysis are superposed on the distribution of UTH.

For the determination of coefficients $a$ and $b$ we follow the method outlined by Schmetz et al. (1995). First, temperature profiles are taken from the NCEP/NCAR Reanalysis (Kalnay et al., 1996) to account for the effect of the temperature lapse rate on the UTH. In a second step, two sets of constant humidity profiles of $40 \%$ and $5 \%$ relative humidity are assumed between $1000 \mathrm{hPa}$ and $100 \mathrm{hPa}$. These temperature and humidity profiles are now inserted into the Synthetic Satellite Radiances (SYNSATRAD) radiative transfer model (Tjemkes and Schmetz, 1997) in order to simulate TB ${ }_{W V}$. The coefficients $a$ and $b$ at each grid point are determined by relating two simulated $\mathrm{TB}_{\mathrm{WV}}$ at $\mathrm{UTH}$ of $40 \%$ and of $5 \%$. The UTH estimation is only possible if clouds are absent in the high and middle levels. Thus the term "clear sky" used for the UTH estimation refers no cloud condition above about the $800 \mathrm{hPa}$ level. The pixel is considered to be cloud-free if window channel brightness temperature is larger than $275 \mathrm{~K}$ (Sohn and Schmetz, 2004) and if the brightness temperature difference between window channel and water vapour channel is larger than $25 \mathrm{~K}$ (Soden, 1998). These thresholds eliminate pixels contaminated by high or middle clouds. A linear relationship approach similar to Eq. (2) is also applied to the $7.3 \mu \mathrm{m}$ channel brightness temperatures for the MTH estimate.

\subsection{Data analysis}

A harmonic analysis is conducted to study the diurnal variations of the precipitation index (PI), high cloud (HC), deep convective cloud (DC), cirrus anvil cloud (CAC), and free tropospheric humidity (UTH and MTH). Since these variables, at the local time of a given day and over a given region, consist of both the diurnal cycle and weather noise, it is necessary to smooth out the weather noise using a large sample size (Duvel and Kandel, 1985). In doing so, daily composites are first prepared by averaging those fields at each time step for a one month period at each grid point. Then, the amplitude and phase of the first diurnal $(24 \mathrm{~h})$ harmonic are estimated by decomposing the obtained daily composite using Fourier analysis.

The diurnal amplitude denotes a half of the value from trough to crest in the first diurnal harmonic and the diurnal phase is defined as the local time showing maximum value. More information regarding the decomposition of diurnal cycle is found in Tian et al. (2004). The results obtained are presented in the following figures using a harmonic dial in which the length of an arrow indicates the amplitude of the first harmonic. The phase showing the maximum can be determined from the orientation of the arrow with respect to a 
(a) Precipitation Index [mm/day]

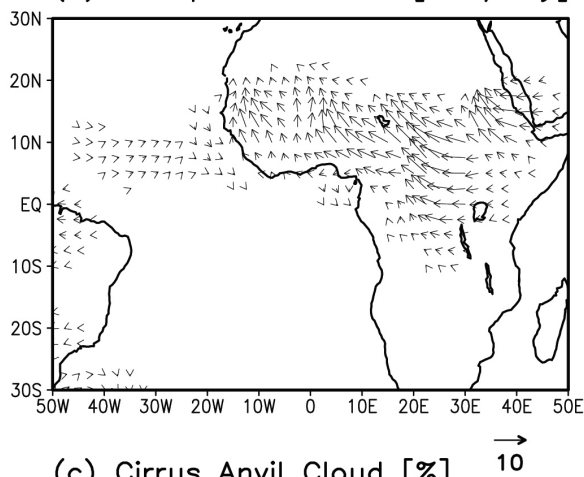

(c) Cirrus Anvil Cloud [\%]

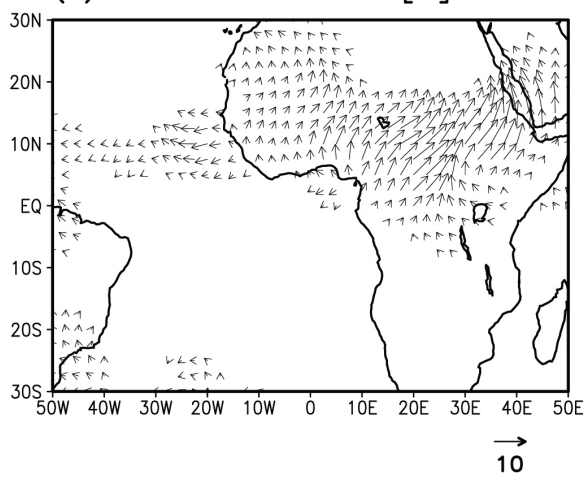

(b) Deep Convective Cloud [\%]

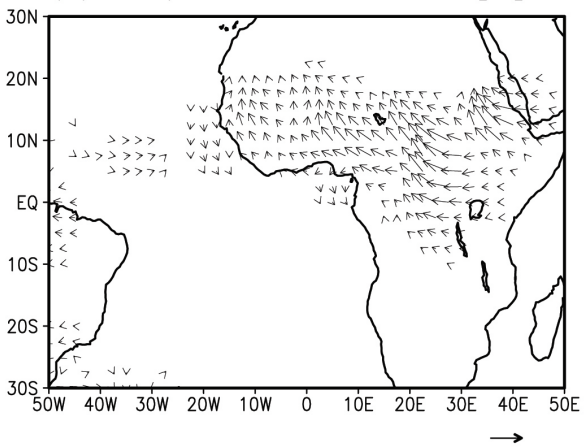

(d) UTH [\%]

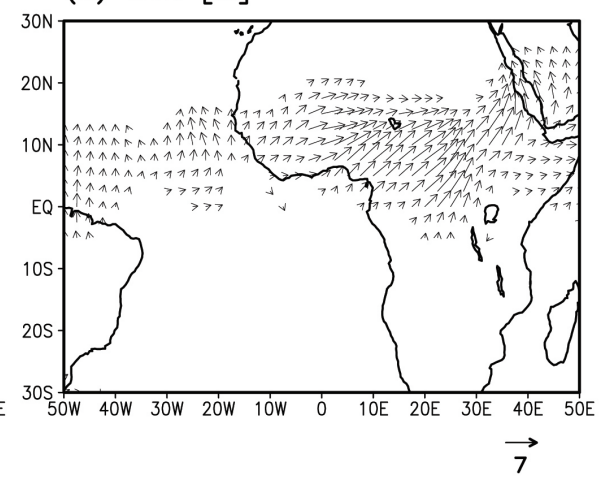

Fig. 2. Diurnal amplitudes and phases of (a) precipitation index, (b) deep convective cloud, (c) cirrus anvil cloud, and (d) UTH for July 2004. The length of the arrow depicts the diurnal amplitude $\left(10 \mathrm{~mm} \mathrm{day}^{-1}\right.$ for precipitation index, $10 \%$ for clouds, and $7 \%$ for UTH).

24-h clock. For example, upward, right, downward, and left pointing arrows denote the maximum at 00:00 LT (midnight), 06:00 LT (dawn), 12:00 LT (noon), and 18:00 LT (sunset), respectively.

We also decompose these variables into a set of empirical orthogonal functions (EOFs) in order to examine significant spatial and temporal features controlling the diurnal variations, from which possible physical processes responsible for diurnal variation can be inferred.

In many previous studies, Eulerian approach has been used for the diurnal variation study. But it is often observed that cloud and humidity features propagate following the large scale circulation, and thus it is of much interest to examine the diurnal variation in Lagrangian framework. Detailed explanation for the Lagrangian approach is given in Sect. 4.

\section{Diurnal variation in Eulerian framework}

A harmonic and EOF analysis are conducted for July 2004 (hereafter July) and January 2005 (hereafter January) at each $2.5^{\circ} \times 2.5^{\circ}$ grid point to document the diurnal variation of PI, HC, DC, CAC, UTH, and MTH over tropical Africa and the adjacent Atlantic Ocean.

The geographical distributions of the monthly mean $\mathrm{TB}_{11}$ (K) and UTH (\%) for July (left panels) and January (right panels) are presented in Fig. 1. The monthly mean $200 \mathrm{hPa}$ wind fields $\left(\mathrm{m} \mathrm{s}^{-1}\right)$ from the NCEP/NCAR Reanalysis are superposed on the UTH field. The distributions of TB $_{11}$ lower than $270 \mathrm{~K}$ are located in Central Africa, the Ethiopian highlands, and West Africa from the Guinea coast to the western Sahel in July, reflecting convective regions along the intertropical convergence zone (ITCZ). These regions are zonally elongated over North Africa. In January, local minima are found in South Africa (e.g. Zaire, Angola, and Zambia) and Brazil, indicating the movement of the convective regions associated with the progress of seasons.

Monthly mean UTH distributions for both months (i.e., July and January) show similar patterns to those of $\mathrm{TB}_{11}$. It is noted that there is a close resemblance between cold $\mathrm{TB}_{11}(<270 \mathrm{~K})$ and high UTH $(>50 \%)$. Also noted is the probable influence of large-scale circulation on the UTH distribution. The upper easterly winds and UTH distributions in July suggest that the upper troposphere over the tropical Atlantic Ocean is influenced by cloud or moisture detrained from deep convection centres over West Africa. On the other hand, prevalent westerlies over the Atlantic Ocean in January may imply that convection in Amazonia and its associated water vapour distribution likely affect the diurnal variation over the Atlantic Ocean. 


\subsection{Harmonic analysis}

Figure 2 presents the diurnal amplitudes and phases of PI, DC, CAC, and UTH in July. HC and MTH are not shown because $\mathrm{HC}$ is the sum of DC and CAC, and because MTH features are very similar to those for UTH. Large diurnal variations are observed over the land areas such as Central Africa, Ethiopian highlands, and the west coast around Guinea and Senegal, corresponding to highly convective areas. Such geographical distributions were also noted by other diurnal variation studies (e.g. Duvel and Kandel, 1985; Duvel, 1989; Machado et al., 1993; Yang and Slingo, 2001; Tian et al., 2004). The largest amplitudes (PI: $\sim 11 \mathrm{~mm}^{-1}{ }^{-1}$, HC: $\sim 16 \%$, DC: $\sim 10 \%$, CAC: $\sim 11 \%$, UTH: $\sim 7 \%$, MTH: $\sim 7.5 \%$ ) tend to occur over elevated terrain areas such as the Ethiopian highlands and Central Africa (Duvel, 1989; Yang and Slingo, 2001). On the other hand, diurnal variations over the convectively inactive subtropical regions appear to be comparatively weak.

During July, the PI maxima occur in the late afternoon to evening period over the convective regions of the land. These are consistent with the local time of precipitation maximum obtained from raingauge measurements in the subSahel area (Pinker et al., 2006). Also found are significant regional variations of the PI phase and amplitude, probably caused by orographic influences and mean easterly winds (Duvel, 1989; Yang and Slingo, 2001). By contrast, the maximum rainfall tends to occur during early morning hours ( $\sim 06: 00$ LT) over the open oceans. The morning preference of oceanic rainfall is consistent with previous studies using passive microwave measurements or radar observations (e.g. Imaoka and Spencer, 2000; Nesbitt and Zipser, 2003; Yang and Smith, 2006). Peaks around the noon to afternoon period are noted over the coastal regions such as the Gulf of Guinea and the offshore regions near the western Sahel. These peaks can be explained by topographical influences on rain formation, as noted in previous studies (e.g. Gambheer and Bhat, 2001; Yang and Slingo, 2001; Zuidema, 2003).

The phases and amplitudes of the diurnal variation of DC are given in Fig. 2b. Despite a rather different definition, the timing of the maximum DC is very similar to that for PI. However, the number of harmonic dials showing the morning peak decreases in comparison to the PI. It is also noted that the ratio of diurnal amplitude between the offshore area and the open oceans is larger than the PI.

The CAC also shows a clear land-sea contrast in phase. The CAC peaks over the land are found during the night (00:00-03:00 LT). These diurnal variations of CAC are similar to those of high clouds (not shown) although high clouds reach their maximum a few hours earlier than CAC. On the other hand, oceanic cloudiness (both HC and CAC) shows maxima around 18:00 LT. The time of the maximum is generally consistent with previous studies (e.g. Duvel, 1989; Udelhofen and Hartmann, 1995; Soden, 2000; Tian et al., 2004).
The convective regions show a noticeable diurnal variation of UTH with a larger amplitude over land, as noted by other studies (Soden, 2000; Tian et al., 2004). Despite the height difference, the diurnal variation of MTH is nearly identical to that of UTH (not shown). The land-sea contrast in the timing of the maximum is revealed. While UTH and MTH tend to peak in the early morning (03:00-06:00 LT) over land, their peaks over the open oceans occur a few hours earlier, i.e., around midnight. The timing of the maximum over land is qualitatively consistent with results from radiosonde observations at local sites (Dai et al., 2002; Machado et al., 2002). Coastal oceanic regions show later peaks compared to the open oceans. The general patterns of UTH diurnal variation are consistent with the results of Soden (2000) and Tian et al. (2004). But those patterns are slightly different from the results of Udelhofen and Hartmann (1995) who reported the UTH maximum occurring around 06:00 LT.

Diurnal amplitudes and phases for January are given in Fig. 3. All parameters show large diurnal amplitudes over South Africa and Brazil, following the seasonal movement of convective centres. Although these convective areas show more homogeneous diurnal harmonics than in the July case, diurnal phases are qualitatively similar to those found in July. However, noticeable differences are found over the ocean, particularly in the South Atlantic Ocean. Outside the oceanic ITCZ, diurnal harmonics with substantial magnitudes are found over areas off the east coast of Brazil, off the west coast of Central to South Africa, and over the areas surrounding Madagascar. Those regions tend to have later peaks of PI in comparison to the equatorial Atlantic Ocean. The morning maxima of UTH and MTH ( 06:00 LT) are found over the oceanic areas off the west coast of Central to South Africa. It appears that advection from South Africa may account for those later peaks - see the wind field given in Fig. 1.

\subsection{Diurnal anomalies}

Diurnal anomalies of precipitation, cloud fractions, and free tropospheric humidity for July are averaged over land and the ocean separately and the results are given in Fig. 4. Grid points with the diurnal standard deviation of UTH less than $1 \%$ are excluded, to reduce the influence of fluctuations that are irrelevant to the diurnal cycle. Vertical bars represent standard errors for each hourly mean. The averaged PI (and DC) anomaly over land increases rapidly after 11:00 LT and reaches a maximum around 18:00 LT. The maximum anomaly of CAC is observed in the nighttime ( $\sim 02: 00 \mathrm{LT})$, i.e. $8 \mathrm{~h}$ after the DC maximum. Diurnal variation of $\mathrm{HC}$ is nearly in phase with that of CAC except for a broad peak in the evening to midnight, suggesting an increase of cloud in lower and warmer parts of the atmosphere at night.

Diurnal anomalies of UTH and MTH with maxima around 03:00 LT are nearly identical over land, although MTH lags a little behind UTH. On the other hand, the minima of free tropospheric humidity are observed between 15:00 LT and 
(a) Precipitation Index [mm/day]

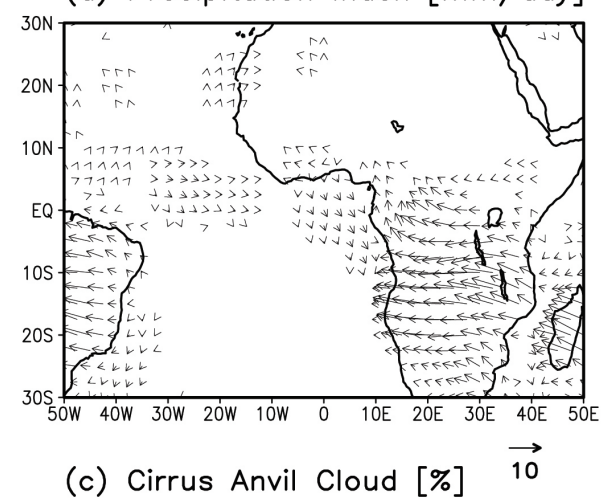

(c) Cirrus Anvil Cloud [\%] 10

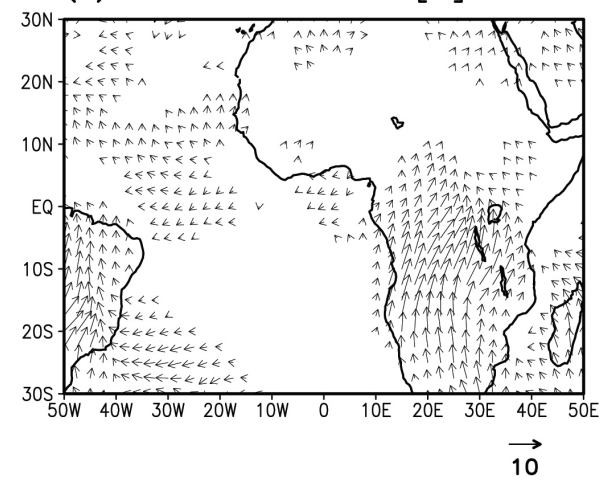

(b) Deep Convective Cloud [\%]

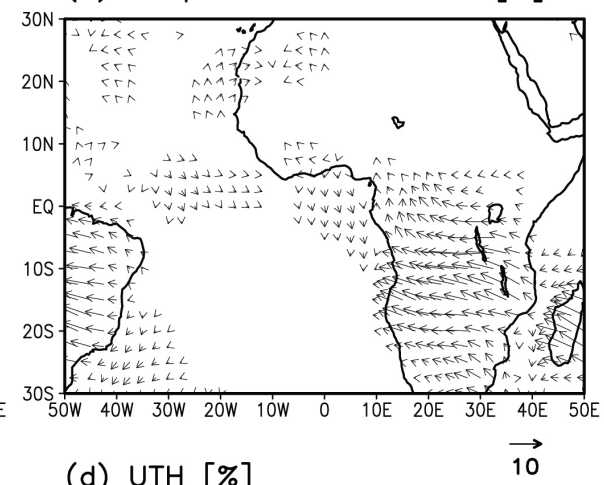

(d) UTH [\%]

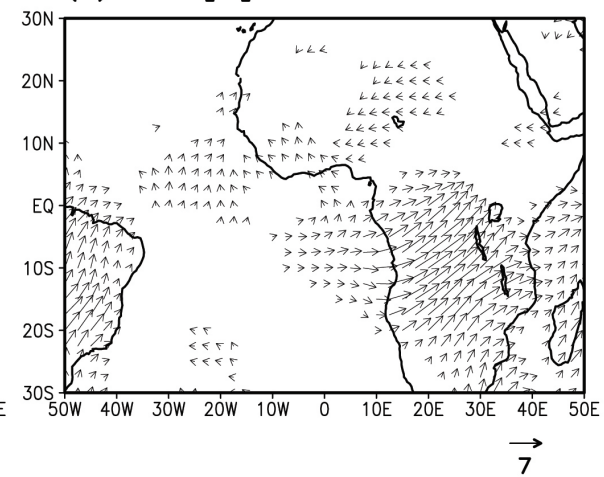

Fig. 3. Same as in Fig. 2, but for January 2005.

18:00 LT during the initial increase in precipitation. This can be explained by the enhanced drying effect of clear-sky pixels in association with the subsidence compensating the convective lifting (Schmetz et al., 2002a). The general trend of UTH follows CAC except for the location of the minimum.

Convective regions in the Atlantic Ocean show an early morning peak of rainfall ( 07:00 LT) in July. Note that amplitudes are smaller and standard errors are relatively larger, suggesting that diurnal variations of the rainfall over the ocean are much weaker than those over land. The DC shows a maximum around 14:00 LT with a secondary maximum around 07:00 LT. Soden (2000) and Tian et al. (2004) examined the time variations of DC colder than $230 \mathrm{~K}$ and showed a slantwise variation of DC over the ocean from the colder upper layer to warmer lower layer with time. Thus, over the ocean, the precipitation peak associated with coldest clouds occurs in the early morning while warmer DCs exhibit their maxima in the afternoon. Thus the different phase between PI and DC in Fig. 4 is due to the larger contribution of colder DC cloud to the PI. By contrast, HC attains its maximum fraction in the late afternoon (17:00-18:00 LT), lagging precipitation by nearly $12 \mathrm{~h}$. Unlike the land case, HC and CAC show a nearly identical peak. This indicates that $\mathrm{HC}$ is mainly composed of CAC, implying that the oceanic convection is weaker than that over land, as noted in Soden (2000) and Liu and Zipser (2005).
Diurnal anomalies of UTH and MTH over the ocean show a broad peak during the night, starting right after $\mathrm{HC}$ and CAC reach their maximum around 18:00 LT. The minima of free tropospheric humidity are found between 12:00 LT and 15:00 LT. Also noted is the larger time lag, around $9 \mathrm{~h}$, between CAC and free tropospheric humidity, in comparison to the much smaller time lag over land.

Diurnal anomalies for January over land are similar to the July case except for a relatively distinct peak of $\mathrm{HC}$ around 19:00 LT - see Fig. 5. The HC reaches a maximum around 19:00 LT and slowly decreases during the night, similar to the precipitation pattern. Seasonal differences in diurnal variation appear to be small over land. Again, a similar trend is shown between CAC and UTH/MTH.

Over the ocean, although cloud fractions show nearly identical variations to the July case, substantial differences in the PI variation are noted. Besides a morning peak around 07:00 LT, another peak with a larger magnitude is found in the afternoon $(\sim 15: 00 \mathrm{LT})$. Examination of diurnal harmonics over offshore regions of southwestern coast of Brazil and Madagascar indicates that PI peaks in the afternoon (Fig. 3a). Although the morning peak is observed over the open oceans, the amplitude is smaller than that over those offshore regions. The afternoon peak over those offshore regions is generally consistent with results from TRMM observations - see Fig. 15a in Yang and Smith (2006). Slight time differences 
Land

Ocean
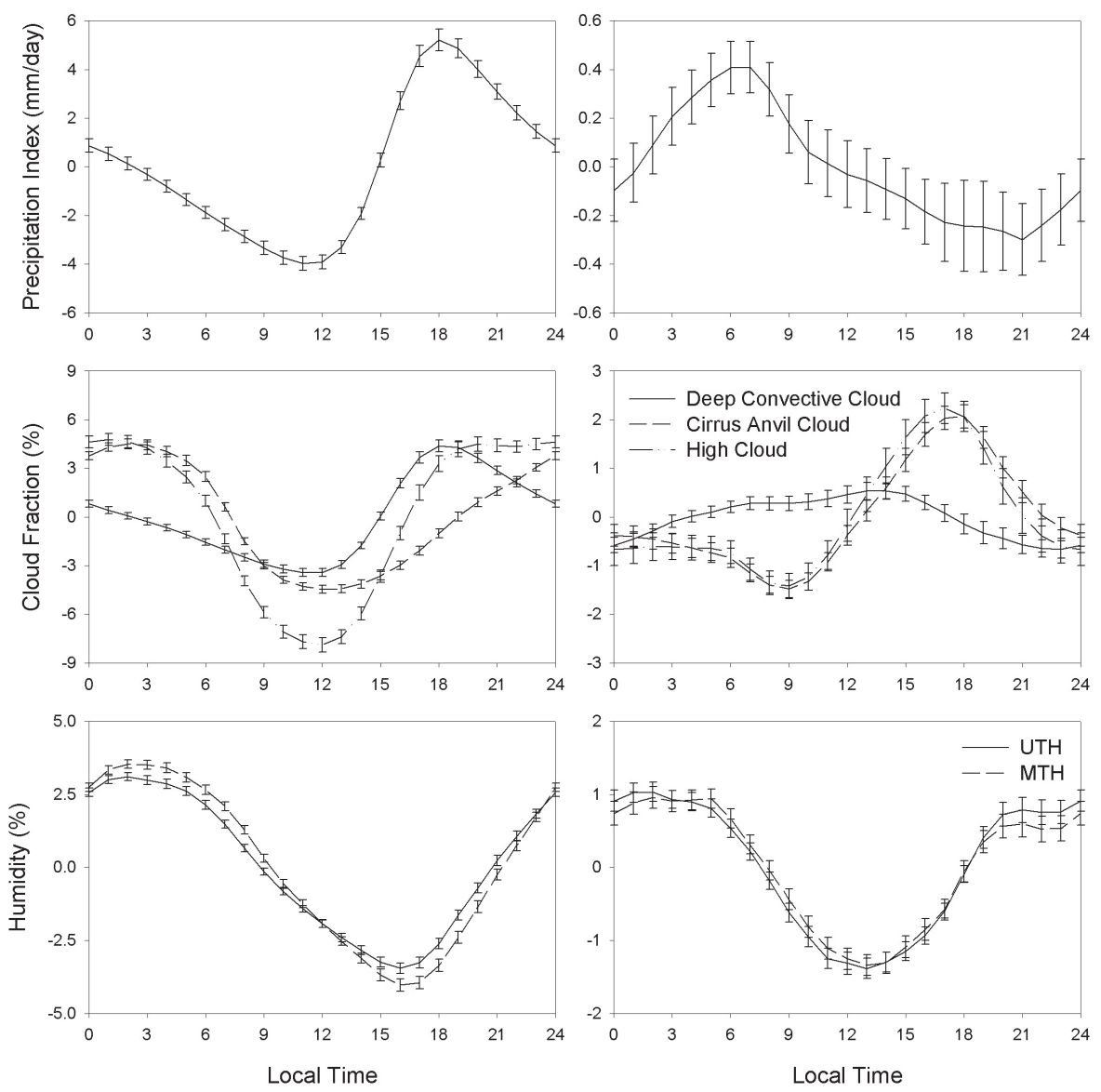

Fig. 4. Diurnal anomalies in precipitation index $\left(\mathrm{mm} \mathrm{day}^{-1}\right)$, clouds $(\%)$, and free tropospheric humidity (\%) for spatial averages over land regions (left) and ocean regions (right) in July 2004. Vertical bars represent the standard errors for each hourly mean.

of maxima are also noted for UTH and MTH, as noted in the July case.

In summary, the results from the harmonic analysis and averaged anomalies indicate that PI (and DC) over land tends to peak generally in the late afternoon to early evening, preceding the CAC maxima by about $9 \mathrm{~h}$. The free tropospheric humidity (both UTH and MTH) over land reaches its maximum in the nighttime, similar to CAC, lagging precipitation and high cloud by about $9 \mathrm{~h}$. Over the ocean, the prevalence of rainfall in the morning is evident except for the area near the coastal regions (e.g. the Gulf of Guinea). However, DC attains the maximum in the early afternoon followed by the $\mathrm{HC}$ and CAC maxima. An evident difference from the land case is that UTH and MTH over the ocean tend to peak $9 \mathrm{~h}$ later than the CAC maximum. Seasonal differences in the timing of maximum appear to be small over both land and the ocean.

It is of importance to note that nearly the same trend occurs between CAC and UTH/MTH in particular after the DC maximum. Such resemblance supports the notion that the evaporation of ice particles from CAC play only a small role in moisturising the upper troposphere, as asserted in Luo and Rossow (2004), and that the ice water contained in the cirrus is too small to account for the moistening of the upper troposphere. Noting that both CAC and UTH tend to increase rapidly after the DC maximum at around 18:00 LT and reach their maxima around 03:00 LT over land, the decay of deep convective cloud seems to be the main source supplying moisture to the upper troposphere as well as creating cirrus anvils. The development of deep convective clouds and their associated updraft transports cloud condensates and water vapour upward into the higher altitudes. By contrast, during the decay period of deep convective clouds, condensates are likely detrained from convection cells into their surroundings following the diverging flow, directly moisturising the upper troposphere while forming cirrus anvil clouds.

\subsection{EOF analysis}

An EOF analysis is conducted in order to examine how geographically varying features of convection and upper 

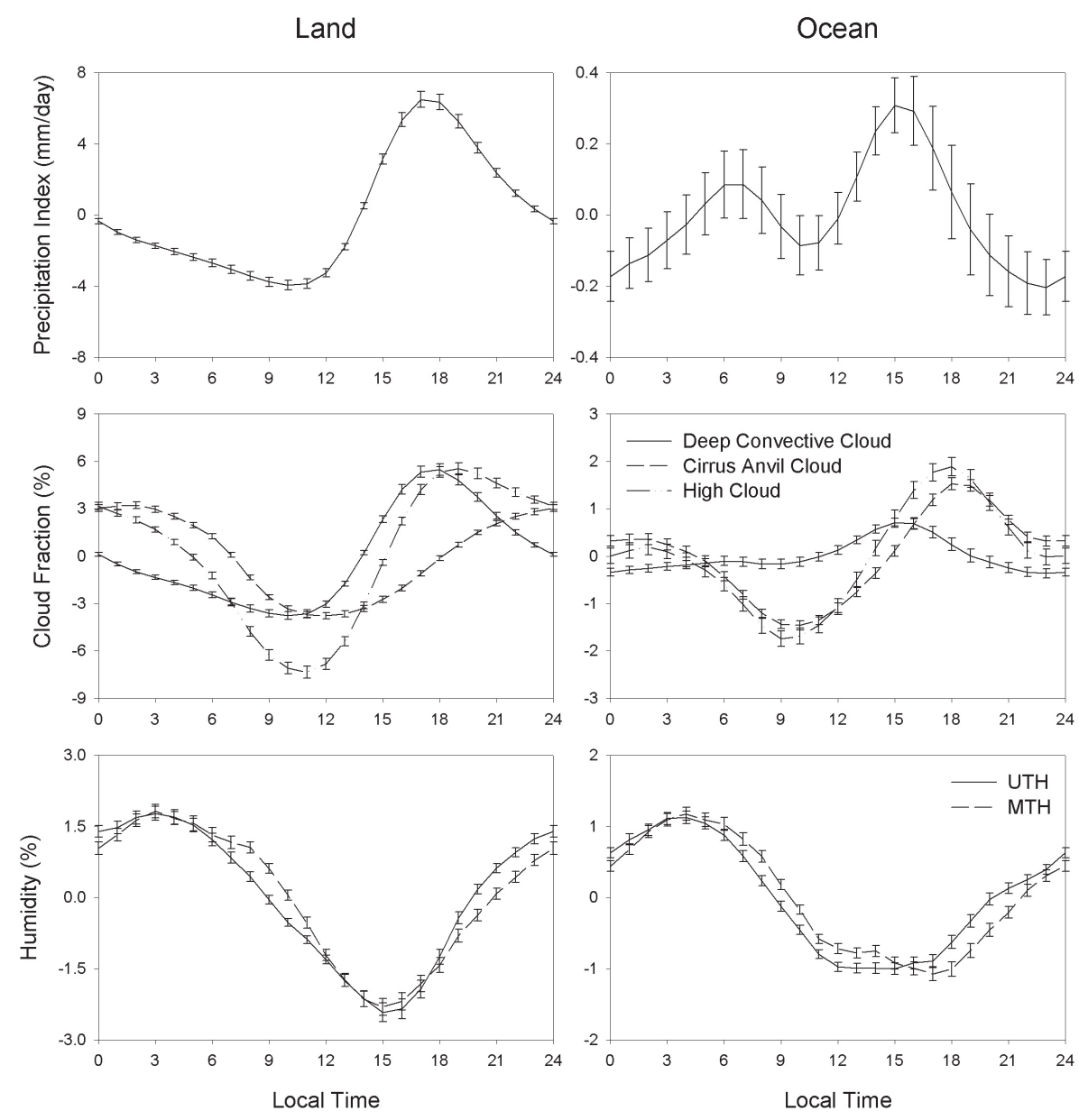

Fig. 5. Same as in Fig. 4, but for January 2005.

tropospheric humidity are related to the temporally varying diurnal cycles shown in the harmonic analysis. It may also help to understand physical processes which may lead to diurnal variations of those parameters.

Figure 6 shows the geographical distributions of two leading EOF modes for the first harmonic components of PI, DC, CAC, and UTH for July. Spatial patterns are smoothed for clarity. The first modes of PI and DC explain around 87\% of the diurnal variations while CAC and UTH explain variations around $80 \%$. The first eigenvectors of PI and DC exhibit similar spatial patterns, in which maximum areas are located over the convective areas in Central Africa. However, smaller magnitudes of eigenvectors are found only over limited oceanic areas off Guinea, with an opposite sign in comparison to that shown in Central Africa. Geographical distributions of the first EOF modes for CAC appear very similar to those for PI and DC.

The principal components of the first mode for PI and DC are similar to each other, with a maximum around 20:00 LT and a minimum around 08:00 LT. Although the first EOF vectors for PI, DC, and CAC look alike, the principal component of CAC is very different from other two (Fig. 7). The CAC tends to have a maximum around 02:00 LT and a minimum around 14:00 LT. This time lag between the maximum of $\mathrm{PI} / \mathrm{DC}$ and CAC can be explained by anvil spreading and/or exposure of the lower part of the high cloud due to the evaporation of the upper part of the convective cloud.

Geographical distributions of the first EOF mode for UTH, in the left bottom panel of Fig. 6, appear to be very similar to the other three (PI, DC, and CAC) except for a more latitudinally elongated pattern extending to the Caribbean Sea along the ITCZ. The explained variance of about $81 \%$ is similar to that for CAC. The first EOF mode for MTH appears to be nearly identical to that for UTH (not shown). Time series of the principal components of UTH and MTH again show nearly the same pattern (Fig. 7a), with maxima around 03:00 LT and minima around 15:00 LT. The principal components of the first EOFs of five variables indicate that the precipitation maximum takes place around 20:00-21:00 LT along with the development of deep convection. The PI maximum is then followed by the CAC maximum with nearly a six hour difference. After one or two hours, the UTH/MTH 
(a)

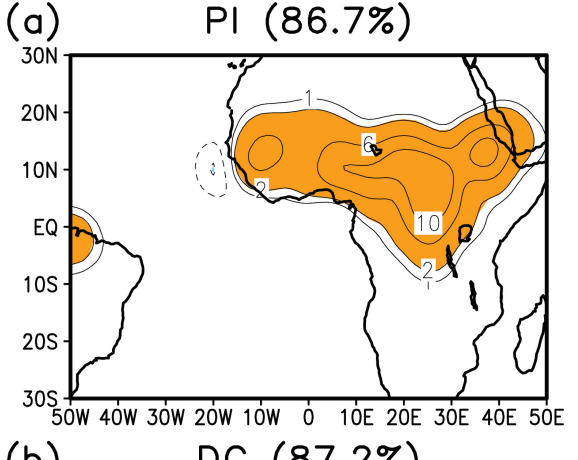

(b)

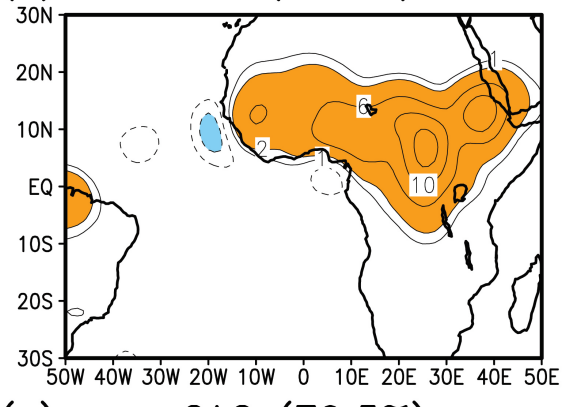

(c)

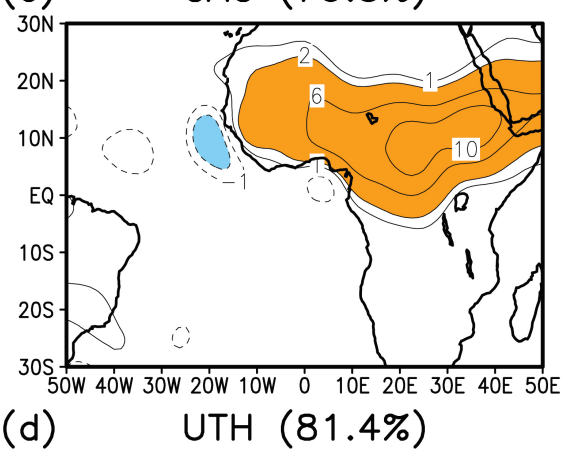

(d)

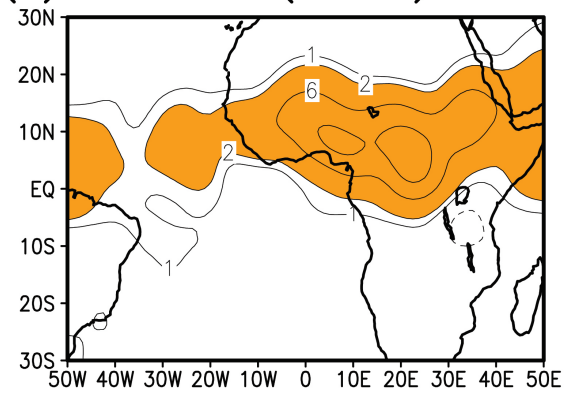

PI (13.3\%)

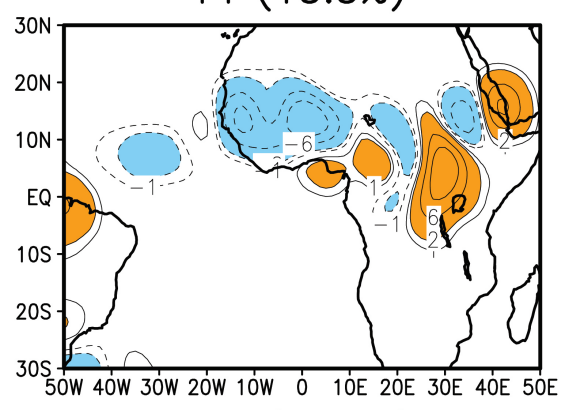

DC (12.8\%)

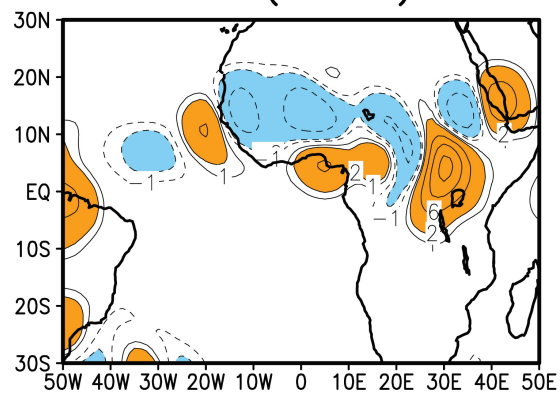

CAC (20.5\%)

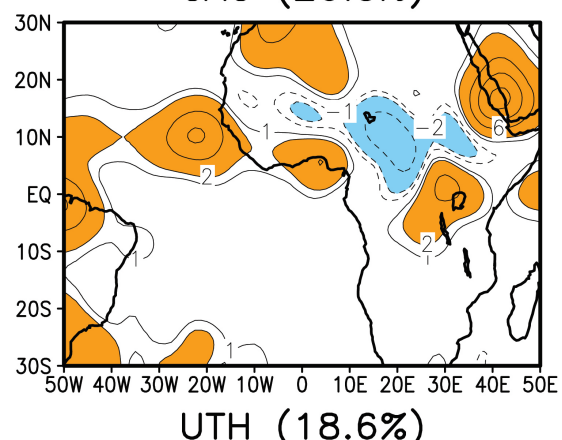

UTH (18.6\%)

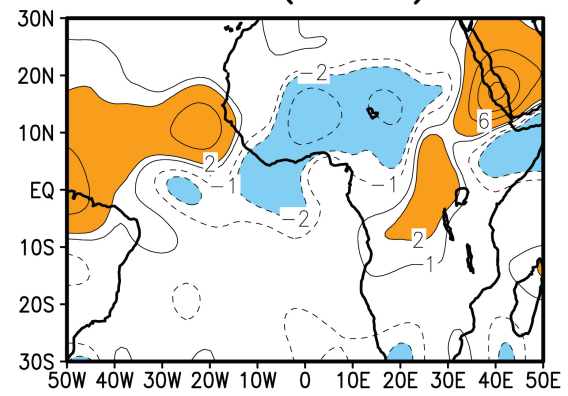

Fig. 6. Spatial patterns of two leading EOF modes: (a) precipitation index, (b) deep convective cloud, (c) cirrus anvil cloud, and (d) UTH. Positive and negative values are represented by solid and dashed lines, respectively. Contour interval is 1 for values between -2 and 2 , and 4 for others.

maxima occur over most of the convective regions over land, showing the $8-9 \mathrm{~h}$ difference from the precipitation maximum.

The right panels of Fig. 6 present the geographical distributions of the eigenvectors for the second EOF modes. The second modes for PI and DC explain about $13 \%$ of the to- tal variance and up to $20 \%$ for CAC and UTH. Thus, diurnal variations are completely resolved by two independent modes. The first EOF appears to be related to land-sea contrast and latitudinal dependence of solar heating, while the weaker second mode is likely to be associated with topographical variations over North Africa. Positive areas are 

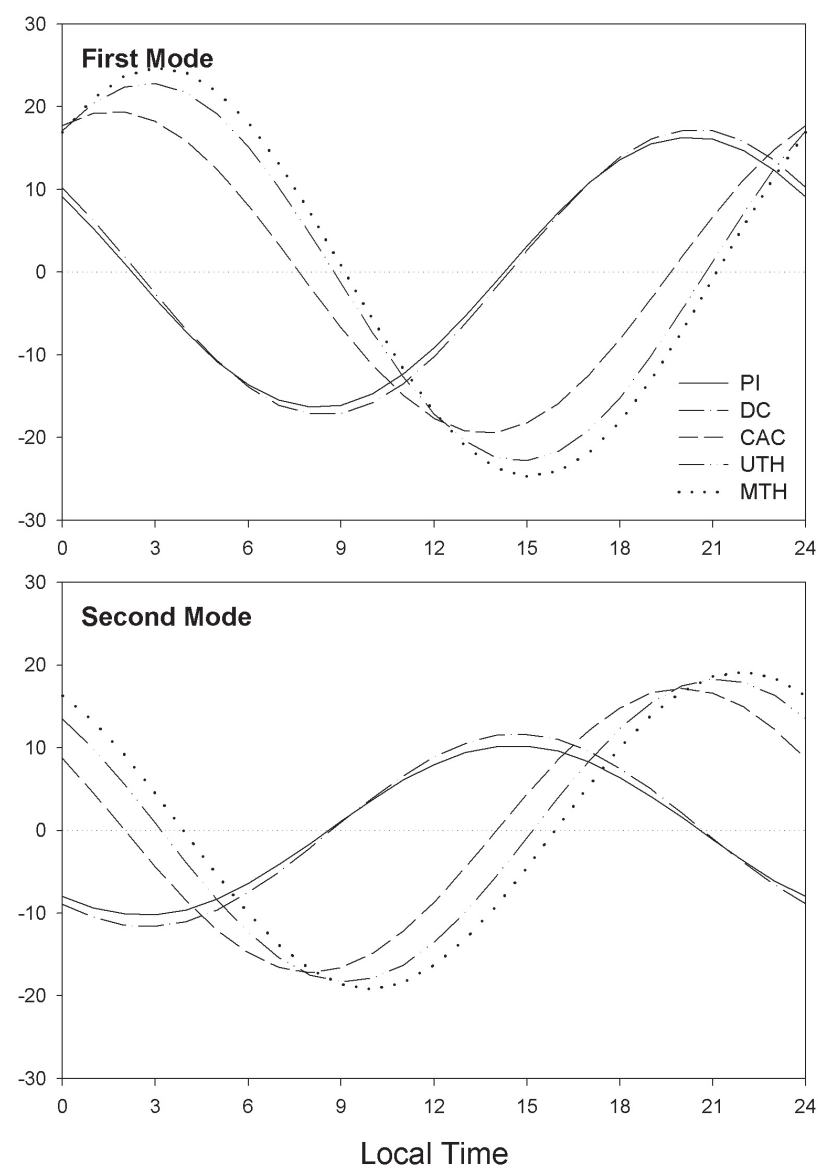

Fig. 7. Time series of corresponding principal components for the first EOF modes (upper panel) and the second EOF modes (lower panel). Principal components for MTH are also included.

more or less situated on high altitudes such as the highlands from Ethiopia to the Arabian Peninsula, relatively high regions from Lake Victoria to west Sudan, and the Central African Republic to Nigeria. In contrast, negative areas of PI and DC are found in the Central African lowland areas such as southeast Sudan, west Chad, and the Sahel. The CAC also shows a similar geographical distribution, but seems to be extended further to the Atlantic Ocean along the ITCZ than PI and DC. It is also of interest to observe that PI and DC show maxima in the early afternoon $(\sim 15: 00$ LT $) 5-6 \mathrm{~h}$ earlier than ones shown in the first mode.

Spatial distribution of the second EOF mode for UTH is close to that for CAC except for Ivory Coast and Ghana, and the adjacent ocean areas. MTH also shows a similar geographical distribution (not shown). Corresponding principal components indicate that UTH and MTH reach maxima in the morning (around 09:00 LT and 10:00 LT) over Central Africa, and around 21:00 and 22:00 LT along the ITCZ in the Atlantic Ocean, respectively. The results appear to be consistent with those from Machado et al. (1993) who reported that small convective cloud cells over West Africa de- velop between 12:00 and 15:00 LT and then grow or merge into larger clusters later.

In this EOF analysis, the same trends of CAC and UTH (and MTH) are also shown with a lag behind DC; i.e.: an early period of moistening (or CAC increase) occurs in the developing period of deep convective clouds whereas a later period of moistening (or CAC increase) corresponds to the decay period of deep convective clouds. However, their eigenvectors show similar features to each other, suggesting that the mechanisms of developing and decaying deep convective cloud are also responsible for CAC and UTH evolution.

\section{Diurnal variation in Lagrangian framework}

Cloud and humidity features in the Meteosat-8 $6.2 \mu \mathrm{m}$ channel measurements are tracked for July 2004 to examine the diurnal variations in a Lagrangian framework. The forward trajectories are constructed by applying a crosscorrelation method to successive images of $6.2 \mu \mathrm{m}$ channel brightness temperatures, as described in Soden (2004). Pattern matching is performed by defining a square target box $\left(400 \times 400 \mathrm{~km}^{2}\right)$ which is composed of roughly 17000 image pixels. The spatial pattern of a target box at time $t=T$ is compared with the patterns in all boxes on the following image $(t=T+\Delta t)$ within a radius of $500 \mathrm{~km}$. The box with the highest spatial correlation at time $t=T+\Delta t$ is determined to be the destination box. The reliability of this search is checked by a backward pattern matching in which the destination box at time $t=T+\Delta t$ is defined as a target box. Pattern tracking is terminated if the backward pattern matching yields a destination box different from the initial target box. If the pattern matching is successful, the destination box becomes the new target box and cross-correlations are calculated with all possible destination boxes at time $t=T+2 \Delta t$.

An example of forward trajectory analysis is given in Fig. 8. Constructed Lagrangian forward trajectories indicate that cloud and humidity features generally make their way into the subtropical subsidence regions, implying that moisture transport occurs from convective regions to subtropical subsidence areas. It is also noted that clouds and water vapour that originate from convective areas over land often propagate westward and thereby may affect the temporal variation of cloudiness and humidity over the tropical Atlantic Ocean.

PI, cloud fractions, and UTH are produced at each box following trajectories, and then averages are taken at each local time bin from diurnal variations over 3500 trajectories. MTH is not considered here because the propagating features obtained from the $6.2 \mu \mathrm{m}$ channel images generally represent the upper tropospheric layer, and the MTH structural patterns are not very different from those of UTH. Diurnal variations obtained for July 2004 are given in Fig. 9. Vertical bars denote the standard error of each hourly mean. Over land, the 
Table 1. The local time of maxima and minima (in parenthesis) of deep convection (precipitation index and deep convective cloud), high cloud, cirrus anvil cloud, UTH, and MTH. Results from Udelhofen and Hartmann (1995), Soden (2000), and Tian et al. (2004) are also included for comparison. $\mathrm{L}$ and $\mathrm{O}$ represent land and ocean, respectively.

\begin{tabular}{|c|c|c|c|c|c|}
\hline & $\begin{array}{l}\text { Udelhofen and Hart- } \\
\text { mann (1995) }\end{array}$ & Soden $(2000)$ & Tian et al. (2004) & \multicolumn{2}{|c|}{ This study } \\
\hline Domain & $\begin{array}{l}15^{\circ} \mathrm{N}-15^{\circ} \mathrm{S} \\
142.5^{\circ} \mathrm{W}-52.5^{\circ} \mathrm{W}\end{array}$ & $\begin{array}{l}30^{\circ} \mathrm{N}-30^{\circ} \mathrm{S} \\
120^{\circ} \mathrm{W}-30^{\circ} \mathrm{W}\end{array}$ & $30^{\circ} \mathrm{N}-30^{\circ} \mathrm{S}$ & \multicolumn{2}{|c|}{$30^{\circ} \mathrm{N}-30^{\circ} \mathrm{S}, 50^{\circ} \mathrm{E}-50^{\circ} \mathrm{W}$} \\
\hline Period & 12-16 August 1991 & June-August 1987 & July 1999 & July 2004 & January 2005 \\
\hline Deep convection & - & $\begin{array}{l}\text { L: } 1800(1000) \\
\text { O: } 0600-0700(2100)\end{array}$ & $\begin{array}{l}\text { L: } 1800-2100(0900) \\
\text { O: } 0900(2100)\end{array}$ & $\begin{array}{l}\text { L: } 1800(1100) \\
\text { O: } 0700 \& 1400(2100)\end{array}$ & $\begin{array}{l}\text { L: } 1700(1000) \\
\text { O: } 1500 \& 0700(2300)\end{array}$ \\
\hline High cloud & $2000(1000)$ & $\begin{array}{l}\text { L: } 1800(1000) \\
\text { O: } 1700(0900)\end{array}$ & $\begin{array}{l}\text { L: } 2100(1200) \\
\text { O: } 1600(0600)\end{array}$ & $\begin{array}{l}\text { L: } 2000(1200) \\
\text { O: } 1700(0900)\end{array}$ & $\begin{array}{l}\text { L: } 1900(1100) \\
\text { O: } 1800(0900)\end{array}$ \\
\hline Cirrus anvil cloud & - & - & - & $\begin{array}{l}\text { L: } 0200(1200) \\
\text { O: } 1800(0900)\end{array}$ & $\begin{array}{l}\text { L: } 0200(1200) \\
\text { O: } 1800(1000)\end{array}$ \\
\hline UTH & $0600(1800)$ & $\begin{array}{l}\text { L: } 2200(1200) \\
\text { O: } 2000(1000)\end{array}$ & $\begin{array}{l}\text { L: } 0300(1500) \\
\text { O: } 0000(1200)\end{array}$ & $\begin{array}{l}\text { L: } 0200(1600) \\
\text { O: } 0200(1300)\end{array}$ & $\begin{array}{l}\text { L: } 0300(1500) \\
\text { O: } 0400(1500)\end{array}$ \\
\hline MTH & - & - & - & $\begin{array}{l}\text { L: } 0200(1600) \\
\text { O: } 0200(1300)\end{array}$ & $\begin{array}{l}\text { L: } 0300(1500) \\
\text { O: } 0400(1700)\end{array}$ \\
\hline
\end{tabular}

diurnal variations appear to be very similar to the ones noted in the Eulerian framework given in Fig. 4. Diurnal variations over the ocean also exhibit qualitatively similar features to those shown in the Eulerian harmonic analysis except $\mathrm{HC}$ whose maximum occurred earlier by about 2-3 h. Besides the different maximum location, PI and DC show amplitudes twice as large as those noted in the Eulerian framework. The diurnal variation of $\mathrm{HC}$ shows a broad peak between 07:00 and 13:00 LT. Such discrepancies in HC suggest that some of the high cloud systems may be advected from land, in response to the mean upper-level wind, while CAC originates in association with the local convective system. Nevertheless, the overall near similarity of diurnal variations of cloud and humidity variables between the Eulerian and Lagrangian frameworks in both land and ocean suggests that the advection effect on diurnal variations at least over the African continent and the adjacent Atlantic Ocean is less significant than the local processes such as daytime solar heating and orography.

\section{Summary and conclusions}

Diurnal variations of upper and middle tropospheric humidity have been examined in conjunction with diurnal variations of precipitation intensity and high clouds (i.e., deep convective cloud plus cirrus anvil cloud) over tropical Africa and the adjacent tropical Atlantic Ocean. For this purpose, Meteosat- 8 measurements for July 2004 and January 2005 are used. The local times of maxima and minima are summarised in Table 1 with a comparison to results from previous studies (e.g. Udelhofen and Hartmann, 1995; Soden, 2000; Tian et al., 2004). In agreement with previous studies, we find that deep convection and high cloud over North

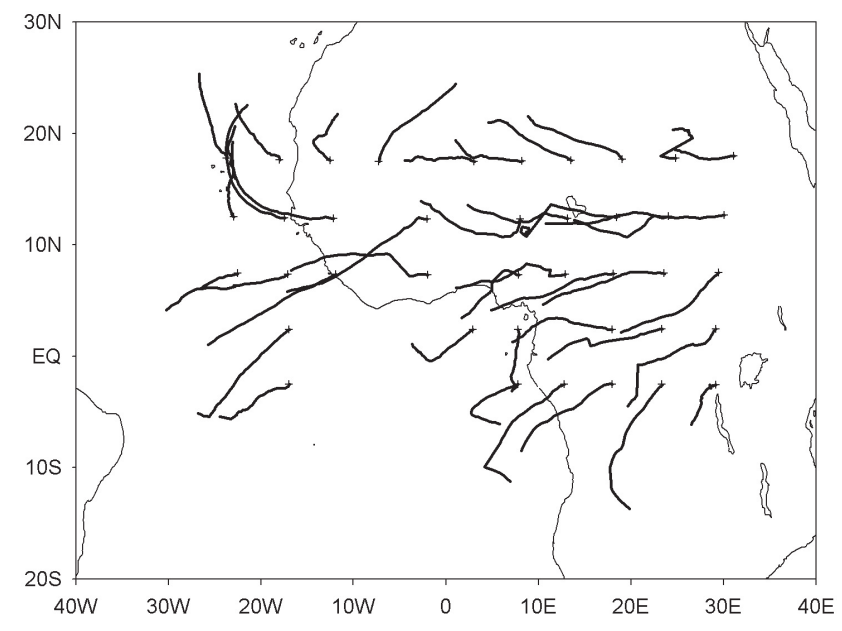

Fig. 8. Examples of Lagrangian forward trajectories constructed from Meteosat-8 6.2 $\mu \mathrm{m}$ channel images. Each cross represents the starting point of each trajectory.

Africa tend to peak generally in the late afternoon and the early evening, respectively. For ocean areas, the PI maximum occurs in the morning, followed by the high cloud maximum in the late afternoon. However, coastal water regions (e.g. the Gulf of Guinea) show a maximum of precipitation in the afternoon. The fact that the UTH diurnal variation is rather similar to deep convection is also generally consistent with previous studies, except for a slight difference over the ocean.

Significant UTH diurnal variations are observed over the convective regions, with a relatively larger diurnal amplitude over land. The UTH tends to reach a peak centered around 02:00-03:00 LT over land. In contrast, a broad peak 

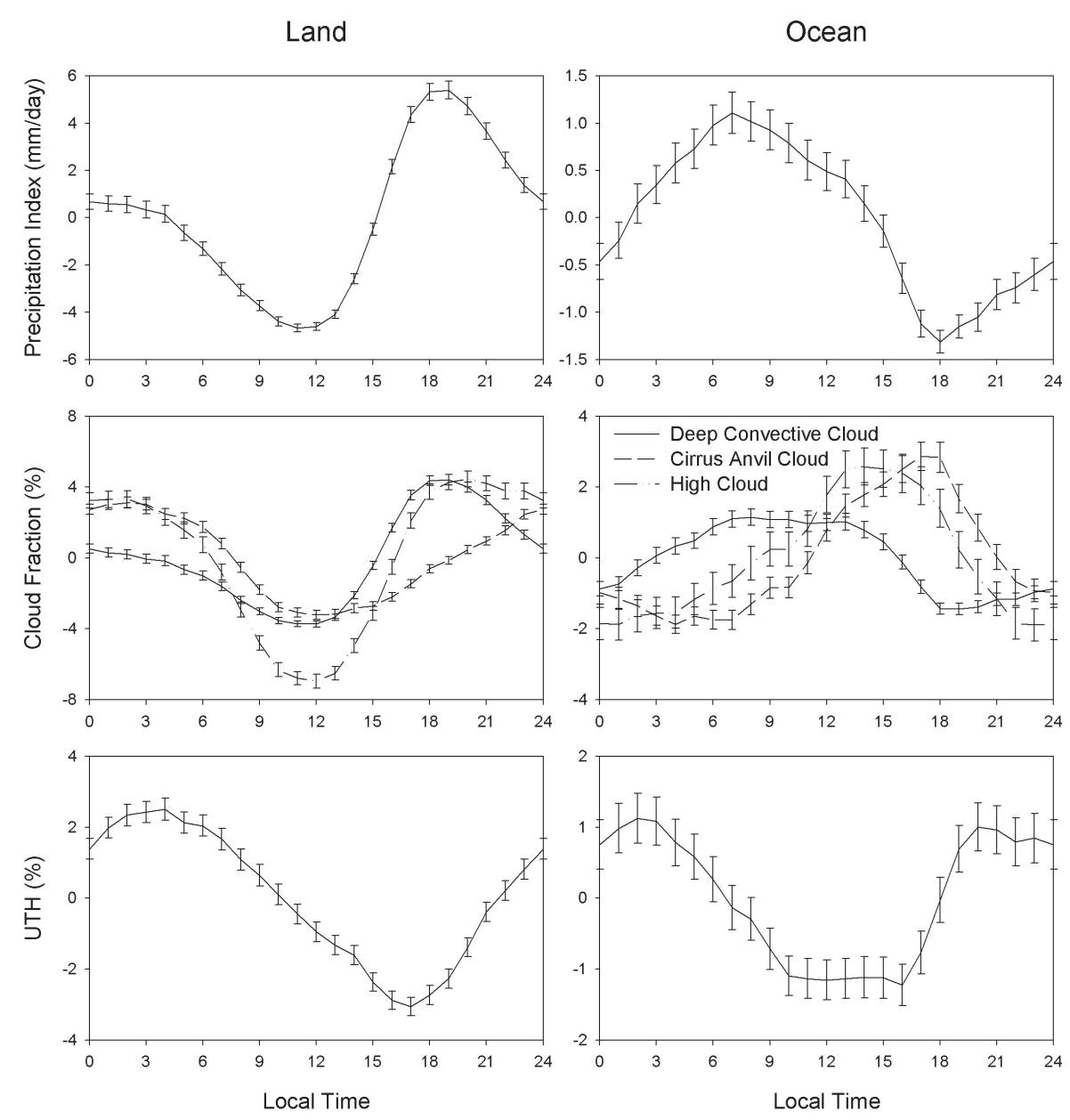

Fig. 9. Lagrangian diurnal variation in precipitation index $\left(\mathrm{mm} \mathrm{day}^{-1}\right)$, clouds $(\%)$, and UTH (\%) averaged from convective trajectories over land regions (left) and ocean regions (right) in July 2004. Vertical bars represent the standard errors for each hourly mean.

during the night is shown over the ocean. Despite the altitude difference, UTH and MTH exhibit nearly identical diurnal variations. It is also noted that the seasonal difference in the diurnal variation is generally small over both land and ocean. Finding that diurnal variations in the Lagrangian framework are very similar to those in the Eulerian framework, we are led to suppose that most of convective activities and their associated moistening in the upper troposphere over the African continent and the tropical Atlantic Ocean are likely to be less affected by advection.

Decomposition of diurnal anomalies using a set of EOFs reveals that diurnal variations of moisture and cloud parameters are mainly associated with continental-scale solar heating. Centres of convective activity are over equatorial Central Africa during the summer, and over equatorial southern Africa during the winter in agreement with the known location of the ITCZ. On the other hand, substantial regional variations of up to $20 \%$ appear to be due to the topography over the North African convective regions. This orographicallyrelated signal seems to develop earlier around the mid- afternoon and merge into stronger and broader continentalscale convection clusters later, forming a precipitation maximum in the late afternoon.

The diurnal variation results obtained from harmonic analysis, EOF analysis, and Lagrangian analysis show a close similarity for the spatial patterns of CAC and UTH, while both CAC and UTH lag behind DC. Analysis indicated that CAC and UTH increase following DC development with a time lag, and then increase continuously during the decay period of deep convection. This similarity between CAC and UTH supports the notion that evaporation from CAC during the decay phase plays only a small role in the moistening the upper troposphere. The mechanism of developing and decaying deep convective cloud appear to be more responsible for the evolution of CAC and UTH. We suggest that the upward transport of water vapour is an integral part of the formation and dissipation of deep convective clouds; as such this process is responsible for the moistening of the upper troposphere. The finding that CAC and UTH increase in a coherent manner after the convection maximum, suggests that 
dissipating deep convective clouds are responsible for the increase, presumably through anvil spreading and the subsequent evaporation of hydrometeors from the deep convective clouds.

Acknowledgements. The authors would like to thank three reviewers for their constructive and valuable comments which led to an improved version of the manuscript. This work has been supported by the Korea Meteorological Administration Research and Development Program under the Grant CATER 2006-2103, and by the BK21 Project of the Korean Government.

Edited by: W. Ward

\section{References}

Bates, J. J., Jackson, D. L., Bréon, F.-M., and Bergen, Z. D.: Variability of tropical upper tropospheric humidity 1979-1998, J. Geophys. Res., 106, 32 271-32 281, 2001.

Chen, S. S. and Houze Jr., R. A.: Diurnal variation and life-cycle of deep convective systems over the tropical Pacific warm pool, Q. J. Roy. Meteorol. Soc., 123, 357-388, 1997.

Dai, A., Wang, J., Ware, R. H., and Van Hove, T.: Diurnal variation in water vapor over North America and its implications for sampling errors in radiosonde humidity, J. Geophys. Res., 107(D10), 4090, doi:10.1029/2001JD000642, 2002.

Duvel, J. P.: Convection over tropical Africa and the Atlantic Ocean during northern summer. Part I: Interannual and diurnal variations, Mon. Wea. Rev., 117, 2782-2799, 1989.

Duvel, J. P. and Kandel, R. S.: Regional-scale diurnal variations of outgoing infrared radiation observed by METEOSAT, J. Clim. Appl. Meteorol., 24, 335-349, 1985.

Gaffen, D. J., Barnett, T. P., and Elliott, W. P.: Space and time scales of global tropospheric moisture, J. Clim., 4, 989-1008, 1991.

Gambheer, A. V. and Bhat, G. S.: Diurnal variation of deep cloud systems over the Indian region using INSAT-1B pixel data, Meteorol. Atmos. Phys., 78, 215-225, 2001.

Gray, W. M. and Jacobson Jr., R. W.: Diurnal variation of deep cumulus convection, Mon. Wea. Rev., 105, 1171-1188, 1977.

Hendon, H. H. and Woodberry, K.: The diurnal cycle of tropical convection, J. Geophys. Res., 98, 16 623-16 637, 1993.

Imaoka, K. and Spencer, R. W.: Diurnal variation of precipitation over the tropical oceans observed by TRMM/TMI combined with SSM/I, J. Clim., 13, 4149-4158, 2000.

Kalnay, E., Kanamitsu, M., Kistler, R., et al.: The NCEP/NCAR 40Year Reanalysis Project, Bull. Am. Meteorol. Soc., 77, 437-471, 1996.

Kondragunta, C. R. and Gruber, A.: Seasonal and annual variability of the diurnal cycle of clouds, J. Geophys. Res., 101, $21377-$ $21390,1996$.

Liu, C. and Zipser, E. J.: Global distribution of convection penetrating the tropical tropopause, J. Geophys. Res., 110, D23104, doi:10.1029/2005JD006063, 2005.

Luo, Z. and Rossow, W. B.: Characterizing tropical cirrus life cycle, evolution, and interaction with upper-tropospheric water vapor using Lagrangian trajectory analysis of satellite observations, J. Clim., 17, 4541-4563, 2004.

Machado, L. A. T., Duvel, J.-Ph., and Desbois, M.: Diurnal variations and modulation by easterly waves of the size distribution of convective cloud clusters over west Africa and the Atlantic Ocean, Mon. Wea. Rev., 121, 37-49, 1993.

Machado, L. A. T., Laurent, H., and Lima, A. A.: Diurnal march of the convection observed during TRMM-WETAMC/LBA, J. Geophys. Res., 107(D20), 8064, doi:10.1029/2001JD000338, 2002.

McClatchey, R. A., Fenn, R. W., Selby, J. E., Volz, F. E., and Garing, J. S.: Optical properties of the atmosphere, Environmental Research Paper No. 354, AFCRL-71-0279, 85 pp, 1971.

Nesbitt, S. W. and Zipser, E. J.: The diurnal cycle of rainfall and convective intensity according to three years of TRMM measurements, J. Clim., 16, 1456-1475, 2003.

Pinker, R. T., Zhao, Y., Akoshile, C., Janowiak, J., and Arkin, P.: Diurnal and seasonal variability of rainfall in the sub-Sahel as seen from observations, satellites and a numerical model, Geophys. Res. Lett., 33, L07806, doi:10.1029/2005GL025192, 2006.

Randall, D. A., Harshvardhan, and Dazlich, D. A.: Diurnal variability of the hydrologic cycle in a general circulation model, J. Atmos. Sci., 48, 40-62, 1991.

Schmetz, J., Geijo, C., Menzel, W. P., Strabala, K., van de Berg, L., Holmlund, K., and Tjemkes, S.: Satellite observations of upper tropospheric relative humidity, clouds and wind field divergence, Contrib. Atmos. Phys., 68, 345-357, 1995.

Schmetz, J., Holmlund, K., König, M., and Lutz, H.-J.: Observation of the diurnal variation of upper tropospheric divergence in a tropical convective system, Paper presented at 6th International Winds Workshop, EUMETSAT, Madison, Wisconsin, USA, 2002a.

Schmetz, J., Pili, P., Tjemkes, S., Just, D., Kerkmann, J., Rota, S., and Ratier, A.: An introduction to Meteosat Second Generation (MSG), Bull. Am. Meteorol. Soc., 83, 977-992, 2002 b.

Schmetz, J., Borde, R., Holmlund, K., and König, M.: Upper tropospheric divergence in tropical convective systems from Meteosat-8, Geophys. Res. Lett., 32, L24804, doi:10.1029/2005GL024371, 2005.

Sherwood, S. C.: On moistening of the tropical upper troposphere by cirrus clouds, J. Geophys. Res., 104, 11 949-11 960, 1999.

Soden, B. J.: Tracking upper tropospheric water vapor radiances: A satellite perspective, J. Geophys. Res., 103, 17 069-17081, 1998.

Soden, B. J.: The diurnal cycle of convection, clouds, and water vapor in the tropical upper troposphere, Geophys. Res. Lett., 27, 2173-2176, 2000.

Soden, B. J.: The impact of tropical convection and cirrus on upper tropospheric humidity: A Lagrangian analysis of satellite measurements, Geophys. Res. Lett., 31, L20104, doi:10.1029/2004GL020980, 2004.

Soden, B. J. and Bretherton, F. P.: Upper tropospheric relative humidity from the GOES $6.7 \mu$ m channel: Method and climatology for July 1987, J. Geophys. Res., 98, 16 669-16688, 1993.

Sohn, B. J. and Schmetz, J.: Water vapor-induced OLR variations associated with high cloud changes over the Tropics: A study from Meteosat-5 observations, J. Clim., 17, 1987-1996, 2004.

Tian, B., Soden, B. J., and Wu, X.: Diurnal cycle of convection, clouds, and water vapor in the tropical upper troposphere: Satellites versus a general circulation model, J. Geophys. Res., 109, D10101, doi:10.1029/2003JD004117, 2004.

Tian, B., Held, I. M., Lau, N.-C., and Soden, B. J.: Diurnal cycle of summertime deep convection over North Amer- 
ica: A satellite perspective, J. Geophys. Res., 110, D08108, doi:10.1029/2004JD005275, 2005.

Tjemkes, S. A. and Schmetz, J.: Synthetic satellite radiances using the radiance sampling method, J. Geophys. Res., 102, 18071818, 1997.

Udelhofen, P. M. and Hartmann, D. L.: Influence of tropical cloud systems on the relative humidity in the upper troposphere, J. Geophys. Res., 100, 7423-7440, 1995.

Yang, G.-Y. and Slingo, J.: The diurnal cycle in the tropics, Mon. Wea. Rev., 129, 784-801, 2001.
Yang, S. and Smith, E. A.: Mechanisms for diurnal variability of global tropical rainfall observed from TRMM, J. Clim., 19, 5190-5226, 2006.

Zuidema, P.: Convective clouds over the Bay of Bengal, Mon. Wea. Rev., 131, 780-798, 2003.

Zveryaev, I. I. and Allan, R. P.: Water vapor variability in the tropics and its links to dynamics and precipitation, J. Geophys. Res., 110, D21112, doi:10.1029/2005JD006033, 2005. 